\title{
The increase in life expectancy in Norway 1985-1998: Good years or bad?
}

\author{
Hans Th. Waaler ${ }^{1}$, Dag Hofoss ${ }^{1}$ and Liv Grøtvedt ${ }^{2}$ \\ ${ }^{1}$ Foundation for Health Services Research, PO Box 55, N-1474 Nordbyhagen, Norway \\ ${ }^{2}$ National Institute of Public Health, Oslo, Norway \\ Corresponding author: Hans Th. Waaler
}

\begin{abstract}
The fear that extra life-years are years of reduced health and health-related quality of life is not supported by our data. From 1985 to 1998 life expectancy for newborns in Norway increased by 1.76 years for females and 2.74 years for males. In the same period, the number of expected years of good or very good health increased by 2.6 years for females and 4.5 years for males. The increase in the number of healthy life years was considerably larger than the increase in the total number of life years won.
\end{abstract}

\section{BACKGROUND}

Norwegians have long been among the longest-living in the world. In the 1960's, Norwegian women had the highest life expectancy in the world, and, although living slightly shorter, Norwegian men too topped the world's life expectancy statistics, together with the Swedes and the Dutch. Over the last decades, however, a number of nations, including Japan and the Mediterranean European countries have been catching up on us $(1,2)$.

Over the last 150 years, the average life expectancy in Norway has increased by more than 30 years. The main reasons are reductions in perinatal deaths and mortality from tuberculosis and a number of other infectious diseases. This primarily reduced mortality among the young. In terms of population life expectancy, future increases in life years must be gained in older age groups. Simulations based on Norwegian mortality tables (not shown here) show that halving the mortality rates among those under 50 today only will produce life-span increments of 1.3 years for women and 0.8 years for men, whereas halving the mortality of persons over 50 will result in life year gains of 5.9 for women and 6.2 for men.

In this article we discuss the quality of the latest gains in life expectancy in Norway. Are the extra lifeyears years of illness, pain and discomfort? Or are they years of good health?

The life spans of each species may be biologically limited, and we may be approaching the limit for human life, which may be 90 years, or maybe 100 (3-5). It may also be argued that ageing partly can be considered an illness which can be cured, in which case people well taken care of may live on to reach maybe 150 years. We are not in the position to pass judgment on such questions, they must be left to biological experts. Our concern is to shed some light on what happens when an already long-lived population gets to live even longer. Does it mean that sick old people are kept alive longer, or does longer lives reflect better population health and not just postponement of death but also of morbidity (6-8)?

One way of studying the question is combining sickness and mortality into one indicator. A number of terms has been coined to describe techniques for doing that, developing indicators to be used to compare health adjusted life spans across nations or social groups, e.g. "Disability adjusted life years" (DALYs), "Health adjusted life years" (HALYs), "Healthy years of life lost" (HYLLs), "Health adjusted life expectancy" (HALE) and "Healthy life expectancy" (HLE). Their core idea is to sort expected life years into years of good health and years of bad health. That makes it possible to treat data on morbidity risk like mortality risk data from mortality tables, and estimate healthy life expectancy in the same way as one traditionally estimate life expectancy. The World Health Organization (9) has recommended estimating healthy life expectancy as an indicator to be used in monitoring progress towards "Health for all by the year 2000".

A number of studies using such measures have been carried out. Most of them are cross-section surveys comparing scores of nations or groups in particular years. Some, however, study trends and compare different points in time. Both in USA 1970-1980 and in England and Wales 1976-1988 the larger part of the increase in the number of expected life years has been shown to be years of disability - and women, living longer than men, to pay the price of spending a larger part of their lives with functional problems $(10,11)$. In Norway 1975-1985, the expected number of healthy life years did not change much, but the extra years of life gained tended to be years with chronic disease (12). Neither in Australia nor New Zealand did the increase in life expectancy during the 1980's produce an increase in healthy life expectancy - here, too, a slight decrease in HLE was found $(13,14)$. In France, however, a larger fraction of life was found to be without disability in 1991 than in 1981 (15). And in 
Thailand, during the decade of rapid economic growth 1986-1995 a marked increase was found in life expectancy as well as in the expected number of years in good health among the elderly (16).

\section{DATA AND METHOD}

This article uses the "Healthy life expectancy"-method suggested by Sullivan (17), with one modification: we used a logistic function to estimate the age-specific values.

We studied the changes in healthy life expectancy on the basis of the national health surveys carried out by Statistics Norway in 1985 and 1998. Approximately 10,000 persons in 1985 and 3500 in 1998 were interviewed in their own homes or by telephone by a calibrated corps of trained census interviewers. The samples were drawn in ways to ensure representativity with respect to the general Norwegian population. The question on which we base this article was: "How do you consider your health: very good, good, neither good nor bad, bad or very bad?"

We based our analysis on the answers given by 3948 men and 4260 women in 1985 and 1667 men and 1767 women in 1998 in the age groups from 16 to 89 years of age. The response rate was $79 \%$ in 1985 and $73 \%$ in 1998 . For the purpose of our analysis, we have, by 5 -year age groups, counted the responses "Good" and "Very good" as one group: the healthy responders, as opposed to those who rated their health "Neither good nor bad", "Bad" or "Very bad" (Table 1). The basic observations were smoothed by means of logistic functions - not because the "biology" follows such a function, but because the fit seems empirically good. The smoothed value for an age-group is equal to $\left(1 /\left(1+\left(b_{0} * b_{1}{ }^{\text {age }}\right)\right)\right.$. The parameter estimates are shown in Table 2 and the smoothed survival (good health) curves in Figure 1.

We based our analyses on the life tables for 1985 and 1998 from Statistics Norway. Into these tables we inserted estimates of frequencies with good and very good health and subtracted the rest from the survivors thereby obtaining estimates of survivors with good and very good health. These calculations gave us life expectancy with good and very good health for the two years.

Even though the national health survey samples of 1985 and 1998 were quite large, the size of each of the 30 gender and age groups in our analysis was limited. For instance, the 1985 survey, which had the largest sample, had data on only 300 females aged 65-69. Of them, 159 , that is $53 \%$, said their health was good or very good. The nominator 159 is supposed to follow a Poisson-distribution. Forty random samples from a Poisson-distribution with the nominators as its parameter were drawn. From these randomly drawn alternative nominators we estimated a variance of the changes in life expectancy from 1985 to 1998.

Table 1. Frequency (\%) of persons 1985 and 1998 reporting good or very good health, by gender.

\begin{tabular}{lllll}
\hline Age & 1985 Males & 1985 Females & 1998 Males & 1998 Females \\
\hline $15-19$ & $94.6(400$ of 423$)$ & $91.5(364$ of 398$)$ & $88.9(112$ of 126$)$ & $93.5(101$ of 108$)$ \\
$20-24$ & $90.7(262$ of 289$)$ & $92.1(327$ of 355$)$ & $90.7(97$ of 107$)$ & $93.5(116$ of 124$)$ \\
$25-29$ & $89.7(306$ of 341$)$ & $91.2(363$ of 398$)$ & $88.7(149$ of 168$)$ & $91.3(157$ of 172$)$ \\
$30-34$ & $89.6(337$ of 376$)$ & $83.8(347$ of 414$)$ & $89.9(170$ of 189$)$ & $87.4(146$ of 167$)$ \\
$35-39$ & $83.1(359$ of 432$)$ & $87.3(386$ of 442$)$ & $88.7(134$ of 151$)$ & $86.5(166$ of 192$)$ \\
$40-44$ & $87.3(322$ of 369$)$ & $79.7(248$ of 311$)$ & $84.0(142$ of 169$)$ & $85.8(157$ of 183$)$ \\
$45-49$ & $81.6(208$ of 255$)$ & $79.1(204$ of 258$)$ & $87.1(136$ of 156$)$ & $80.0(128$ of 160$)$ \\
$50-54$ & $76.7(178$ of 232$)$ & $65.8(154$ of 234$)$ & $80.3(114$ of 142$)$ & $76.5(120$ of 157$)$ \\
$55-59$ & $66.4(168$ of 253$)$ & $66.5(177$ of 266$)$ & $64.7(77$ of 119$)$ & $73.6(81$ of 110$)$ \\
$60-64$ & $63.1(173$ of 274$)$ & $67.5(193$ of 286$)$ & $79.8(67$ of 84$)$ & $67.5(56$ of 83$)$ \\
$65-69$ & $56.7(140$ of 247$)$ & $53.0(159$ of 300$)$ & $76.1(67$ of 88$)$ & $68.2(60$ of 88$)$ \\
$70-74$ & $62.1(144$ of 232$)$ & $55.1(124$ of 225$)$ & $61.2(41$ of 67$)$ & $54.6(48$ of 88$)$ \\
$75-79$ & $57.6(72$ of 125$)$ & $47.8(97$ of 203$)$ & $69.9(37$ of 53$)$ & $56.9(37$ of 65$)$ \\
$80-84$ & $65.6(40$ of 61$)$ & $56.5(70$ of 124$)$ & $64.5(20$ of 31$)$ & $57.7(30$ of 52$)$ \\
$85-89$ & $69.2(27$ of 39$)$ & $56.5(26$ of 46$)$ & $58.8(10$ of 17$)$ & $59.2(16$ of 27$)$ \\
\hline
\end{tabular}

Table 2. Survival (good health) by age: regression coefficients.

\begin{tabular}{lcccrccc}
\hline Dependent variable & Method & $\mathrm{R}^{2}$ & d.f. & \multicolumn{1}{c}{$\mathrm{F}$} & Sig F & $\mathrm{b}_{0}$ & $\mathrm{~b}_{1}$ \\
\hline Male85 & LGS & 0.833 & 13 & 64.93 & 0.000 & 0.0460 & 1.0346 \\
Female85 & LGS & 0.903 & 13 & 121.55 & 0.000 & 0.0460 & 1.0387 \\
Male98 & LGS & 0.844 & 13 & 70.60 & 0.000 & 0.0554 & 1.0288 \\
Female98 & LGS & 0.954 & 13 & 272.56 & 0.000 & 0.0369 & 1.0388 \\
\hline
\end{tabular}




\section{RESULTS}

From 1985 to 1998, life expectancy for Norwegian newborns $\left(\mathrm{E}_{0}\right)$ increased by 1.76 years for women and 2.74 years for men (Table 3 ). This corresponds to a reduction in mortality risk over the age categories throughout life of $17 \%$ for women and $18 \%$ for men. The number of healthy life years increased considerably more than did the total number of life years. Although the percentages of both sexes reporting good or very good health decrease by age, the number of expected years in good or very good health increased by 2.72 for women and 3.08 for men $(p<0.001)$. The Poisson-based distributions of changes in life expectancy with good health are shown in Figure 2.

\section{DISCUSSION}

Our analysis is based on subjective data - self-reported health - and not on physicians' diagnoses, laboratory values, patient records or number or length of hospitalizations. In this connection, however, that is no problem. Self-reported health is a valid measure of general health and correlates highly with probabilities of illness, mortality and use of health services (18-22).

The response rate was lower in 1998 (79\%) than in $1985(73 \%)$. If this means that relatively more 1998responses were given by persons with favourable opinions of their own health - which might be the case if sick persons are over-represented among the slowly but continually growing group who refuse to volunteer data - we may have over-estimated the improvement. We do not have data on the health of the nonresponders. We have nevertheless performed two checks. First, we have looked for covariation across counties of response rate and the percentage reporting good or very good health. There was no such covariance: a lower response rate did not go together with fewer respondents reporting bad health. We also re-calculated our results under the hypothesis that first all and then none of the non-responders were to report having good or very good health. It of course affected the size of the change from 1985 to 1998. It did not, however, affect its direction.

Table 3. $\mathrm{E}_{0}$-values 1985 and 1998. Total and good years of life.

\begin{tabular}{lrc}
\hline & Males & Females \\
\hline Total 1985 & 72.80 & 79.52 \\
Good life 1985 & 63.19 & 65.17 \\
Difference & 9.61 & 14.35 \\
Total 1998 & 75.54 & 81.28 \\
Good life 1998 & 66.27 & 67.89 \\
Difference & 9.27 & 13.39 \\
Added total years 1985-1998 & 2.74 & 1.76 \\
Added good years 1985-1998 & 3.08 & 2.72 \\
p-values (t-test, 40 simulations) & $<0.001$ & $<0.001$ \\
\hline
\end{tabular}
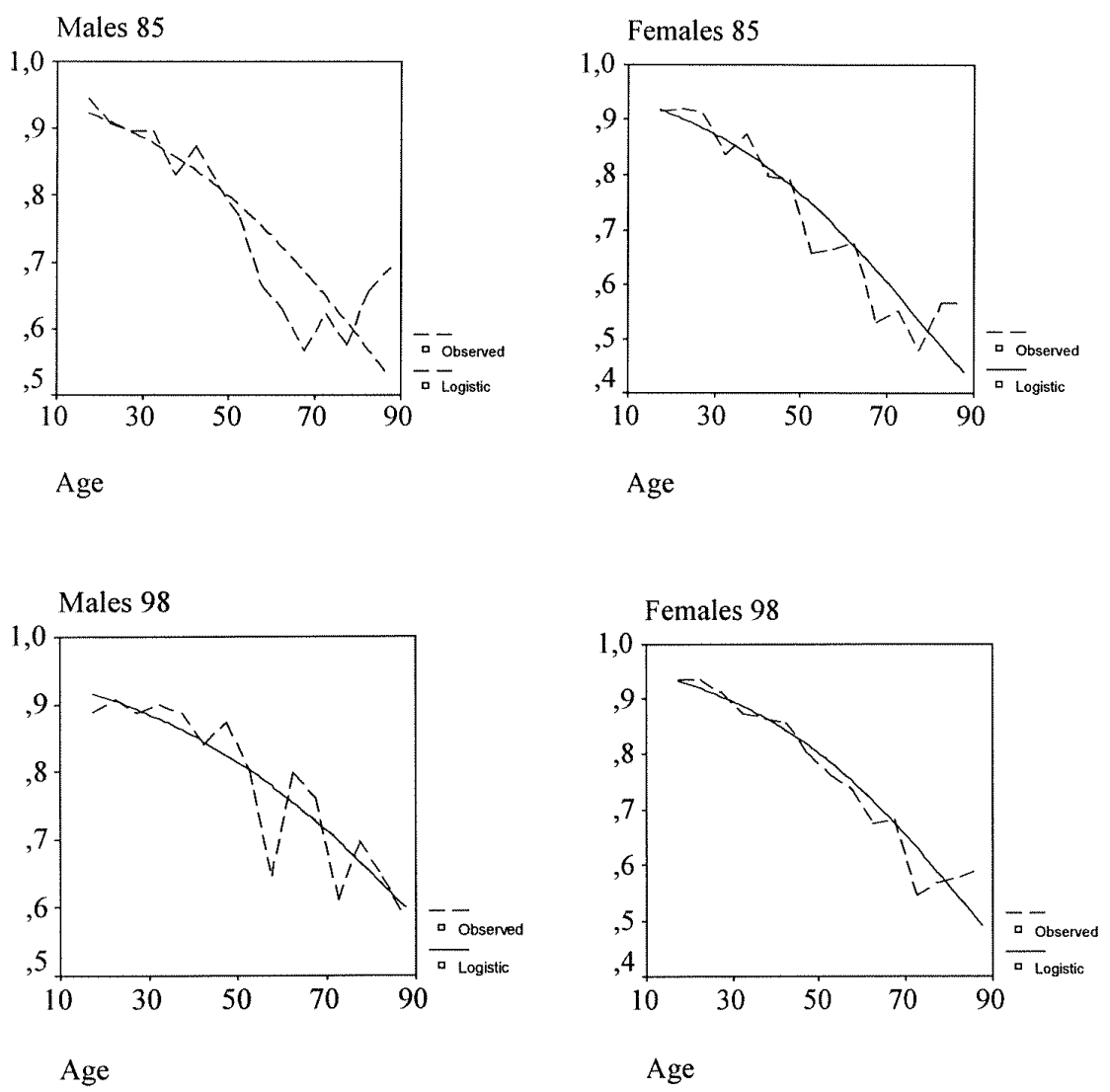

Figure 1. Observed and logistically smoothened distributions of fraction of population alive. By gender and age, 1985 and 1998. 
Both national health survey data sets were collected by interviews in the responders' own homes and did not include institutionalized persons. Not having data on elderly people living in nursing homes we have surely overestimated the percentage of Norwegians in good or very good health. The important question for our purpose is, however, did relatively more Norwegians live in nursing homes in 1998 than in 1985. The answer is no. The number of nursing home beds decreased in the period studied, from 46,455 in 1985 to 43,196 in 1998. During the same period, the population increased slightly, so that the percentage of senior citizens in nursing homes went down from $1.1 \%$ in 1985 to $1.0 \%$ in 1998 . Because of the trend towards caring for senior citizens in their own homes, and the fact that the number of old Norwegians grow rather rapidly, the number of nursing home beds per 1000 persons 67 years or more decreased from 81.4 in 1985 to 69.6 in 1998 (23-25). This probably means that the 1998-sample contains relatively more, and not fewer, responders in less than good health in 1998 than in 1985 , and that we are more likely to have underestimated the improvement than having overestimated it.

As mentioned above, the gender and age specific probabilities of reporting less than good health were based on not very many responders, and therefore subject to random error. We have modeled that error by regarding the age effect coefficients which we estimated from the sample data as random picks from a Poisson distribution of nominators, using the average of 40 Poisson-simulated coefficient values for our calculations of the decrement curves for health by age. In many age groups, the probability of reporting good or very good health was very high. In our simulations, we restricted the coefficients not to predict more than $100 \%$ reporting good or very good health. There was, however, no lower limit. Our estimates of the percen- tage in each gender and age group reporting good or very good health are thus more likely to have been too pessimistic than too optimistic. The randomness of the simulation, however, is unlikely to have produced different biases in the two data sets, and should thus not have affected the size of the change from 1985 to 1998.

An interval of 13 years is not much for studying general time trends. In the two national health surveys prior to 1985 (1968 and 1975), the question on selfreported general health was unfortunately not included. On the other hand, the fact that 13 years were enough to identify a change, may reflect a rather strong improvement in the self-reported general health of Norwegians.

We conclude, therefore, that Norwegians have experienced not only an increase in life expectancy, but an even stronger increase in the expected number of years with good or very good health. Our data do not support the fear that living longer will mean having more years in bad health.

It must be noted that this does not mean that the burden of illness is reduced, neither for the individual nor for society. The fact that the number of healthy life years increases more than the total number of life years is good news. Yet, when people live longer, each may live more years in bad health, even though those years constitute a smaller fraction of their lives. What we have shown is that each Norwegian enjoys reduced risks of mortality and bad health. Still, new cohorts may well live more years in bad health as they live to get older than those who went before them; it is only their risk of death and health problems that is reduced. But that is no little thing - neither to them nor to peoples whose life expectancy is not yet equal to that of the richest nations. At least under Norwegian circumstances, longevity does not mean prolonged frailty.

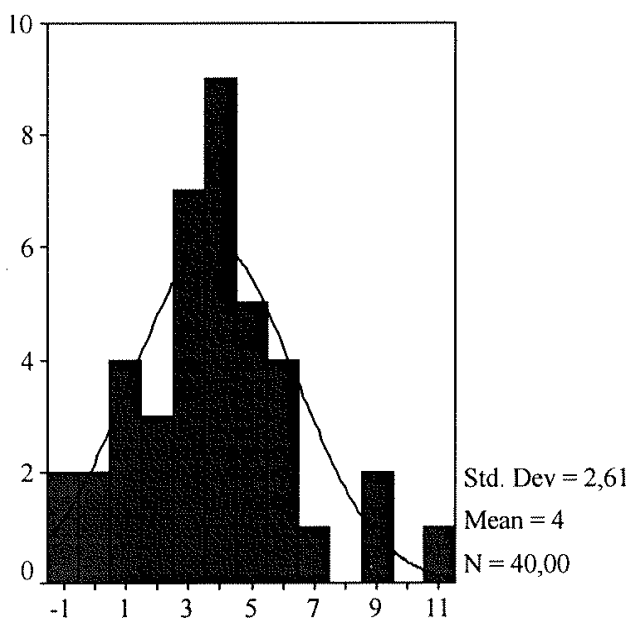

Males

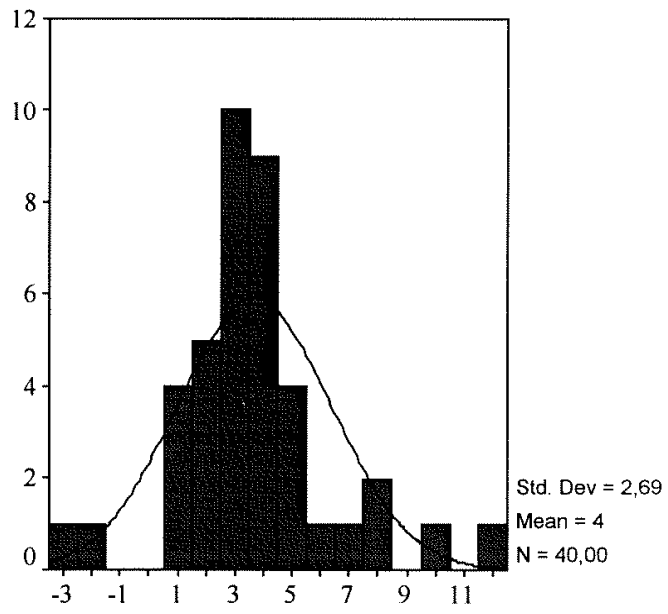

Females

Figure 2. Distribution of changes from 1985 to 1998 in life expectancy with good health, by gender. 


\section{REFERENCES}

1. Waaler HT, Guldvog B. Utviklingen i dødeligheten i Norge - et internasjonalt perspektiv. Tidskr Nor Lageforen 1996; 116: 1104-6.

2. Waaler HT, Guldvog B. Utviklingen av dødeligheten i Norge. Et internasjonalt perspektiv - dødsårsakene. Tidskr Nor Laegeforen 1996; 116: 656-61.

3. Hayflick L. Current theories of biological ageing. Fed Proc 1975; 34: 9-13.

4. Hayflick L. How and why we age. Exp Gerontol 1998; 33: 639-53.

5. Hayflick L. The future of ageing. Nature 2000; 408: 267-9.

6. Fries JF. Aging, natural death, and the compression of morbidity. $N$ Engl J Med 1980; 303: 130-5.

7. Fries JF. The compression of morbidity. Milbank $Q$ 1983; 61: 397-419.

8. Fries JF. The compression of morbidity: near or far? Milbank $Q$ 1989; 67: 208-32.

9. World Health Organization: Development of indicators for monitoring progress towards health for all by the year 2000. Health for all series [4]. Geneva: WHO, 1981.

10. Crimmins EM, Saito Y, Ingegneri D. Changes in life expectancy and disability-free life expectancy in the United States. Popul Dev Rev 1989; 15: 235-66.

11. Bebbington AC. The expectation of life without disability in England and Wales: 1976-88. Popul Trends 1991; 66: 26-9.

12. Grøtvedt L, Viksand G. Life expectancy without disease and disability in Norway. In: Mathers CD, McCallum J, Robine JM (editors). Advances in health expectancies: proceedings of the $7^{\text {th }}$ meeting of the International Network on Health Expectancy (REVES). Canberra, Australia: Australian Institute of Health and Welfare, 1994.

13. Mathers CD. Trends in health expectancies in Australia 1981-1993. J Aust Popul Assoc 1996; 13: 1-15.

14. Davis P, Graham P, Pearce N. Health expectancy in New Zealand, 1981-1991: social variations and trends in a period of rapid social and economic change. J Epidemiol Community Health 1999; 53: 519-27.

15. Robine JM. Disability-free life expectancy trends in France 1981-1991, international comparison. In: Mathers CD, McCallum J, Robine JM (editors). Advances in health expectancies: proceedings of the $7^{\text {th }}$ meeting of the International Network on Health Expectancy (REVES). Canberra, Australia: Australian Institute of Health and Welfare, 1994.

16. Jitapunkul S, Chayovan N. Healthy life expectancy of Thai elderly: did it improve during the soap-bubble economic period? J Med Assoc Thai 2000; 83: 861-4.

17. Sullivan DF. A Single Index of Mortality and Morbidity. HSMHA Health Rep 1971; 86: 347-54.

18. Mossey JM, Shapiro E. Self-rated health: a predictor of mortality among the elderly. Am J Public Health 1982; 72: 800-8.

19. Kaplan GA, Camacho T. Perceived health and mortality: A nine-year follow-up of the Human Population Laboratory cohort. Am J Epidemiol 1983; 117: 292-304.

20. Fylkesnes K, Førde OH. Determinants and dimensions involved in self-evaluation of health. Soc Sci Med 1992; 35: 271-9.

21. Fylkesnes K. Determinants of health care utilization - visits and referrals. Scand J Soc Med 1993; 21: 40-50.

22. Kaplan GA, Goldberg DE, Everson SA, Cohen RD, Salonen R, Tuomilehto J, et al. Perceived health status and morbidity and mortality: evidence from the Kuopio ischaemic heart disease risk factor study. Int $J$ Epidemiol 1996; 25: 259-65.

23. Statistics Norway. Health statistics 1985 (NOS B681). Oslo: Statistisk sentralbyrå, 1987.

24. Statistics Norway. Social statistics 1985 (NOS B685). Oslo: Statistisk sentralbyrå, 1987.

25. Statistics Norway. Nursing statistics 1998 (NOS C559). Oslo: Statistisk sentralbyrå, 2000. 